\title{
Development of an Enhanced Self-Tuning RBF-PID Controller for Achieving Higher Energy-Efficient Process Control
}

\author{
Zu Wang1 , Liang Xia ${ }^{1}$, John Kaiser Calautit ${ }^{2}$, Xinru Wang ${ }^{1,3}$, Danwei Jiang ${ }^{1}$, Song Pan ${ }^{4}$, \\ Jinshun $\mathrm{Wu}^{5}$ \\ ${ }^{1}$ Research Centre for Fluids and Thermal Engineering, University of Nottingham, Ningbo, China \\ ${ }^{2}$ Department of Architecture and Built Environment, The University of Nottingham, Nottingham, UK \\ ${ }^{3}$ College of Emergency Technology and Management, North China Institute of Science \& Technology, Langfang, China \\ ${ }^{4}$ Beijing Key Laboratory of Green Built Environment and Energy Efficient Technology, Beijing University of Technology, Beijing, \\ China \\ ${ }^{5}$ Hebei Province Renewable Energy Heating and Cooling Cogeneration International Union Research Center, North China \\ Institute of Science \& Technology, Langfang, China \\ Email: *Liang.Xia@nottingham.edu.cn
}

How to cite this paper: Wang, Z., Xia, L. Calautit, J.K., Wang, X.R., Jiang, D.W., Pan, S. and Wu, J.S. (2021) Development of an Enhanced Self-Tuning RBF-PID Controller for Achieving Higher Energy-Efficient Process Control. Journal of Building Construction and Planning Research, 9, 272-291. https://doi.org/10.4236/jbcpr.2021.94017

Received: May 13, 2021

Accepted: November 12, 2021

Published: November 15, 2021

Copyright (c) 2021 by author(s) and Scientific Research Publishing Inc. This work is licensed under the Creative Commons Attribution International License (CC BY 4.0).

http://creativecommons.org/licenses/by/4.0/

\begin{abstract}
Proportional, integral and derivative (PID) control strategy has been widely applied in heating systems in decades. To improve the accuracy and the robustness of PID control, self-tuning radial-basis-function neural network PID (RBF-PID) is developed and used. Even though being popular, during the control process both of PID and RBF-PID control strategy are inadequate in achieving simultaneous high energy-efficiency and good control accuracy. To address this problem, in this paper we develop and report an enhanced self-tuning radial-basis-function neural network PID (e-RBF-PID) controller. To identify the superiority of e-RBF-PID, following works are conducted and reported in this paper. Firstly, four controllers, i.e., on-off, PID, RBF-PID and e-RBF-PID are designed. Secondly, in order to test the performance of the e-RBF-PID controller, an experimental water heating system is constructed for being controlled. Finally, the energy consumption for the four controllers under the three control scenarios is investigated through experiments. The experimental results indicate that in the three scenarios, the developed e-RBF-PID controller outperforms on-off controller as having higher accuracy. Compared to the PID controller, the e-RBF-PID controller has higher speed in control, and the experimental results show that settling time savings is between $12.6 \%$ - 49.0\%. Most importantly, less control energy consumption is obtained if using the e-RBF-PID controller. It is found that up to $28.5 \%$ energy con-
\end{abstract}


sumption can be saved. Therefore, it is concluded that the proposed e-RBF-PID is capable of enhancing energy efficiency during control process.

\section{Keywords}

Energy-Efficient Control, RBF Neural Network, Enhanced Self-Tuning PID, Experimental Validation

\section{Introduction}

\subsection{Conventional PID Controller}

On-off and proportional, integral and derivative (PID) control strategy has been widely used in industrial control process. In particular, PID control strategy has gained an extensive application in various thermal engineering systems, for instance, heat exchanger [1], refrigeration system [2] [3] and heating, ventilation and air-conditioning (HVAC) system [4] [5]. In these previous researches, controller based on PID control strategy has simple structure and effective control has been achieved. Aredehali et al. [6], Aredehali et al. [7] and Jahedi and Ardehali [8] developed a PID controller to control indoor air temperature of a modelled thermal zone. The simulation results indicated that the PID controller had a good tracking performance as indoor air temperature became gradually closed to the reference temperature. Soyguder et al. [9] adopted two PID controllers to adjust indoor air temperatures of two modelled thermal zones respectively. The simulation results demonstrated that the two controllers were effective in temperature control. Attaran et al. [10] established a decoupled HVAC system and designed two separate PID controllers for the regulation of indoor air temperature and humidity. In the aforementioned studies, the PID gain coefficients used in PID controllers were not sufficiently effective because the static error was not eliminated [6]-[10]. Further, the selected PID coefficients were not satisfactory to achieve energy-efficient control, leading to high energy consumption in the control process.

In the above literatures [1]-[10], authors conducted tuning or applied tuned PID gain coefficients for obtaining better performance and higher energy-efficiency of PID controllers. Through these previous publications, researchers found that tuning PID gain coefficients was valuable. However, tuning was always time-consuming and sometimes expensive [11] [12] [13] [14]. In order to fix the problems, self-tuning has been developed and largely applied in PID controllers.

\subsection{Self-Tuning PID Control}

In self-tuning PID controllers, the gain coefficients are automatically tuned based on established update rules. The update rules tell how PID gain coefficients should be varied based on the gap between the actual and expected performance. As shown by Wu et al. [15], Beyhan and Alc1 [16] and Zhang et al. 
[17], PID gain coefficients were instantly updated by a numerical searching tool, which is gradient descent algorithm. In these studies, the deviation of the real performance from the desired performance was quantified and then PID coefficients were automatically adjusted accordingly in order to minimize the performance deviation.

\subsection{Self-Tuning Radial-Basis-Function Neural Network Controller}

In all the self-tuning PID controllers, self-tuning RBF-PID controller has gained an extensive application because of its higher performance. In $\mathrm{Wu}$ et al. [15], Beyhan and Alc1 [16] and Zhang et al. [17], PID controllers were integrated with a system identifier, namely radial-basis-function neural network (RBFNN). RBFNNs are a black-box approach with the following advantages. Firstly, RBFNNs usually yielded accurate modelling result and RBFNNs were very effective in approximating polynomials [18]. Secondly, RBFNNs consume small computing time and space as they normally have only one hidden layer. Thirdly, because of the utilization of Gaussian-function in the hidden layer, RBFNNs have a rapid convergence. Therefore, RBFNNs are good at quickly and precisely mapping a numerical relationship between system inputs and outputs, even for nonlinear and more complicated system.

\subsection{Novelty and Originality}

The following describes the novelty and originality of this paper, given in three points. The point 1 shows the necessity of establishing new energy consumption indicators for controllers and how these indicators can aid to examine the performance of controllers. The point 2 highlights the demand of double-objective tuner in real life. The point 3 underlined another novelty point of this paper: the performance of controllers is investigated based on experimental system, which is different from most studies.

- Point 1: Establishing new energy consumption indicators for controllers.

In literatures, it is found that previous researchers always investigate the overall control performance from initial-state time and ending time [6] [7] [8] [19] [20]. However, very few studies focus on performance of controllers from the initial value of the controlled output to its target value. A complete control process, which could be split into two periods: unsteady-state and steady-state period. The unsteady-state period is regarded as the period from initial-state time to settling time. The steady-state period is regarded as the one from settling time to end time. In the unsteady-state period, a controlled output is adjusted to approach its desired level. During the steady-state period, the controlled output is maintained at the desired level and therefore the system runs in steady-state, yielding constant energy consumption. However during the unsteady-state period, the trajectory of the controlled output would be largely varied if using different control strategy, causing difference in the energy consumption.

The energy efficiency of controllers in unsteady-state period is vital. In a very 
large number of situations, it is highly possible that a controlled output is often in unsteady-state because of unavoidable disturbances. For instance, in conventional buildings such as offices, metro-stations and shopping centre, unpredictable occupants' behaviours and flow, and weather can easily cause indoor air temperature to deviate from a desired level. In such cases, the controlled output, i.e., indoor air temperature can often be in unsteady-state. Thus, how to increase the energy efficiency of controllers in unsteady-state period is valuable but not adequately investigated in literature.

- Point 2: Developing a special double-objective tuner.

In order to meet the global target of energy conservation and environment protection, the demand of increasing energy efficiency of controllers in unsteady-state period but also achieving good control accuracy in steady-state period shall be simultaneously satisfied. In [15] [16] [17] [19]-[24], RBF-PID controller was integrated with a single-objective tuner, which aimed to reduce the error between controlled output and the reference level. This approach has gained a great success and RBF-PID controller is able to offer high control accuracy. However, it is still necessary to further enhance the energy efficiency of RBF-PID controller. To author's knowledge, there is no research reporting the feasibility of integrating RBF-PID controller with a double-objective tuner in order to simultaneously achieve high energy efficiency in unsteady-state period and high control accuracy in steady-state period.

- Point 3: Investigating RBF-PID controller in practice.

Additionally, it is noticed that the performance of previously established RBF-PID controller in [19] [20] [21] [22] is assessed only by simulation and experimental results on the controller performance are still inadequate. Therefore, in this paper experimental study would be conducted for comparing the performance of RBF-PID controller and the developed e-RBD-PID controller.

\subsection{Aim and Objectives}

In this paper an enhanced self-tuning RBF-PID (e-RBF-PID) controller is developed for achieving higher energy-efficient control. The developed e-RBF-PID controller has a double-objectives tuner in order to simultaneously achieve high energy efficiency in unsteady-state period and good control accuracy in steady-state period. This paper is organized as follows. In the following Section 2 , the experimental heating system is described. In Section 3, a RBFNN and four controllers: on-off, PID, RBF-PID, e-RBF-PID are introduced. Section 4 shows the experimental results and compare energy performance of four controllers. In Section 5, conclusion based on the results of this study is reported.

\section{System Modelling and Controller Development}

\subsection{Development of RBFNN}

In this paper, a RBFNN is used to model the performance of experimental water tank. The structure of RBF identifier is shown in Figure 1. 


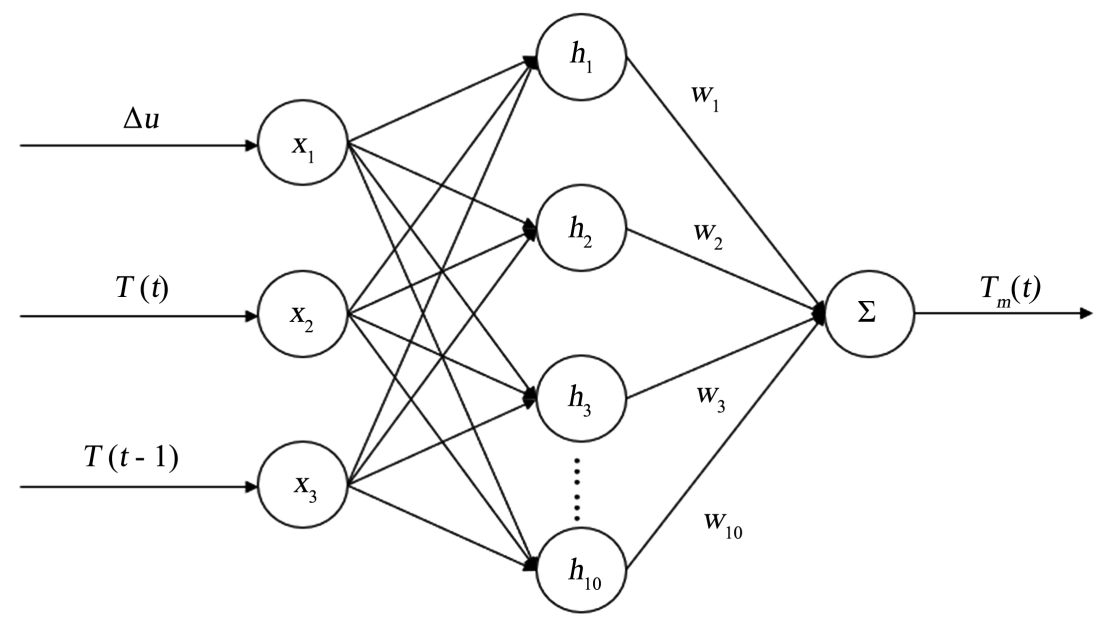

Figure 1. Structure of RBFNN used in this study.

The RBFNN as shown in Figure 1 has three layers: input, hidden and output layer. The inputs of RBFNN is composed of three variables: the variation of controller output $\Delta u$, the water temperature $T(t)$ at the time $t$ and the water temperature at the last time $T(t-1)$. The input vector is $X=[\Delta u, T(t), T(t-1)]^{\mathrm{T}}$. The number of hidden nodes is 10 in this study. The output of $j$ th node in the hidden layer is,

$$
h_{j}=\exp \left(-\frac{\left\|X-C_{j}\right\|^{2}}{2 b_{j}^{2}}\right), j=1,2, \cdots, 10
$$

where $c_{j}$ is the center vector in $j$ th node, given by $C_{j}=\left[c_{j 1}, c_{j 2}, c_{j 3}\right]^{\mathrm{T}}$ and $b_{j}$ is the band width of the $j$ th node. The weight of $j$ th node is $w_{j}$ and the weight vector of the hidden layer is $W=\left[w_{1}, w_{2}, \cdots, w_{10}\right]^{\mathrm{T}}$. The output of RBFNN is the prediction of water temperature, $T_{m}(t)$.

$$
T_{m}(t)=\sum_{j=1}^{10} w_{j} h_{j}
$$

The Jacobian information $J(t)$ is computed by using the following Equation (3),

$$
J(t)=\frac{\partial T(t)}{\partial u(t)} \approx \frac{\partial T_{m}(t)}{\partial u(t)}=\sum_{j=1}^{m} w_{j} h_{j} \frac{c_{j i}-\Delta u(t)}{b_{j}^{2}}
$$

\subsection{On-Off Controller}

On-off controller is established as shown in Equations (4) and (5).

$$
\begin{gathered}
e(t)=T_{\text {ref }}-T(t) \\
u(t)=\left\{\begin{array}{l}
100, e(t)>0 \\
0, e(t) \leq 0
\end{array}\right.
\end{gathered}
$$

\subsection{PID Controller}

The incremental form of PID control is: 


$$
\begin{aligned}
u(t)= & u(t-1)+K_{p}(t)(e(t)-e(t-1))+K_{i}(t) e(t) \\
& +K_{d}(t)(e(t)-2 e(t-1)+e(t-2))
\end{aligned}
$$

where $K_{p}(t), K_{i}(t)$ and $K_{d}(t)$ are proportional, integral and derivative gain coefficients at the time $t$. In addition, Equation (7) is also applied during the experiments.

$$
u(t)=\left\{\begin{array}{l}
0, u(t)<0 \\
u(t) \\
100, u(t)>100
\end{array}\right.
$$

\subsection{RBF-PID Controller}

Following Equations (8)-(10) show how the gain coefficients $K_{p}(t), K_{i}(t)$ and $K_{d}(t)$ in self-tuning RBF-PID controller are instantly tuned. The incremental term $\Delta K(t)$ in Equations (8)-(10) are computed according to the gradient descent method as presented in Equations (11)-(14). Following this method, the three gain coefficients are updated towards the direction in which the error performance index $E(t)$ would be minimized.

$$
\begin{gathered}
K_{p}(t)=K_{p}(t-1)+\Delta K_{p}(t) \\
K_{i}(t)=K_{i}(t-1)+\Delta K_{i}(t) \\
K_{d}(t)=K_{d}(t-1)+\Delta K_{d}(t) \\
E(t)=\frac{1}{2} e(t)^{2} \\
\Delta K_{p}(t)=-\eta_{1} \frac{\partial E}{\partial K_{p}}=\eta_{1} e(t) J(t)(e(t)-e(t-1)) \\
\Delta K_{i}(t)=-\eta_{2} \frac{\partial E}{\partial K_{i}}=\eta_{2} e(t) J(t) e(t) \\
\Delta K_{d}(t)=-\eta_{3} \frac{\partial E}{\partial K_{d}}=\eta_{3} e(t) J(t)(e(t)-2 e(t-1)+e(t-2))
\end{gathered}
$$

where $\eta_{1}, \eta_{2}$ and $\eta_{3}$ are respectively the learning rate of $K_{p}, K_{i}$ and $K_{d}$. In this study, they are set as $10^{-3}, 10^{-6}$ and $10^{-2}$.

\section{5. e-RBF-PID Controller}

The developed e-RBF-PID control system is illustrated in Figure 2. For the experimental water-heating system, the controlled output $u(t)$ directly determines the energy input for heating and therefore influences water temperature but also energy consumed in heating process. Therefore, the optimization of $u(t)$ should cover the above double objectives, i.e., less energy consumed in unsteady-state period and good control accuracy in steady-state period. The tunning rules of e-RBF-PID are presented in Equations (15)-(17). The term $\partial E / \partial K$ is related to the precision of temperature control and $\partial u / \partial K$ is related to energy consumption for controllers in unsteady-state period. 


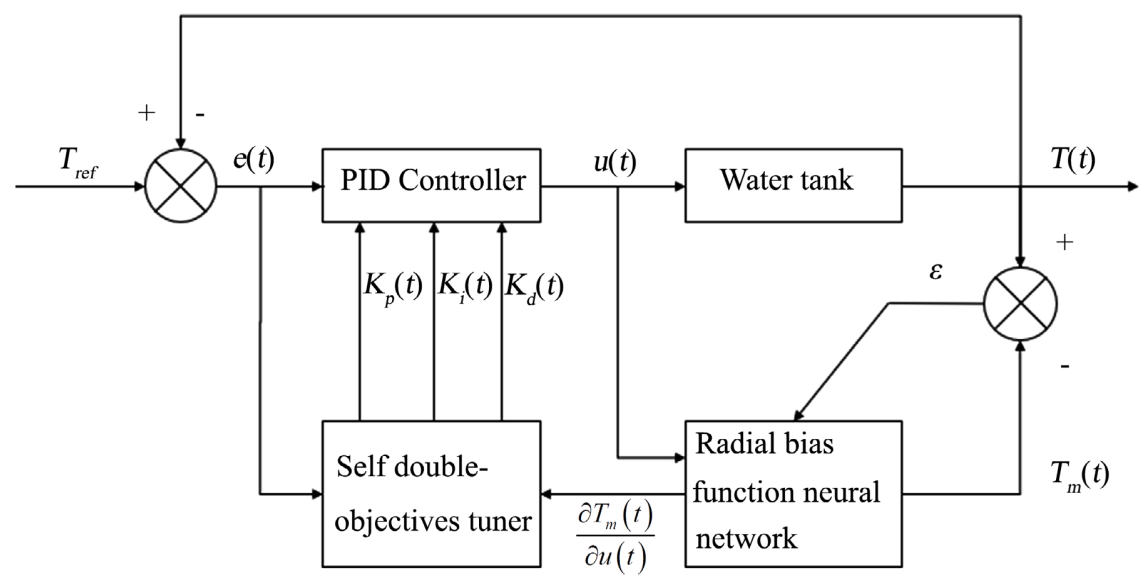

Figure 2. Schematic diagram of e-RBF-PID control system.

$$
\begin{aligned}
\Delta K_{p}(t) & =-\eta_{1}\left(\frac{\partial E}{\partial K_{p}}+\frac{\partial u}{\partial K_{p}}\right)=-\eta_{1}\left(\frac{\partial E}{\partial e} \frac{\partial e}{\partial T} \frac{\partial T}{\partial u} \frac{\partial u}{\partial K_{p}}+\frac{\partial u}{\partial K_{p}}\right) \\
=-\eta_{1} & \frac{\partial u}{\partial K_{p}}\left(\frac{\partial E}{\partial e} \frac{\partial e}{\partial T} \frac{\partial T}{\partial u}+1\right)=\eta_{1}(e(t)-e(t-1))(e(t) J(t)-1) \\
\Delta K_{i}(t) & =-\eta_{2}\left(\frac{\partial E}{\partial K_{i}}+\frac{\partial u}{\partial K_{i}}\right)=-\eta_{2}\left(\frac{\partial E}{\partial e} \frac{\partial e}{\partial T} \frac{\partial T}{\partial u} \frac{\partial u}{\partial K_{i}}+\frac{\partial u}{\partial K_{i}}\right) \\
& =-\eta_{2} \frac{\partial u}{\partial K_{i}}\left(\frac{\partial E}{\partial e} \frac{\partial e}{\partial T} \frac{\partial T}{\partial u}+1\right)=\eta_{2} e(t)(e(t) J(t)-1) \\
\Delta K_{d}(t) & =-\eta_{3}\left(\frac{\partial E}{\partial K_{d}}+\frac{\partial u}{\partial K_{d}}\right)=-\eta_{3}\left(\frac{\partial E}{\partial e} \frac{\partial e}{\partial T} \frac{\partial T}{\partial u} \frac{\partial u}{\partial K_{d}}+\frac{\partial u}{\partial K_{d}}\right) \\
& =-\eta_{3} \frac{\partial u}{\partial K_{d}}\left(\frac{\partial E}{\partial e} \frac{\partial e}{\partial T} \frac{\partial T}{\partial u}+1\right) \\
& =\eta_{3}(e(t)-2 e(t-1)+e(t-2))(e(t) J(t)-1)
\end{aligned}
$$

\subsection{Energy Consumption Indicators}

In this paper, the energy consumed in unsteady-state period, namely unsteady-state energy $E_{u s}$ is calculated using Equation (18). Settling time, $t_{s}$, is defined as the time period of the unsteady state. In the experiments, duty-cycle is computed and sent to the PWM chip every one second. For the experimental system in this study, the term $U(t) \times I(t)$ is equal to approximately 450 watts in average. As shown in Equation (18), the overall energy consumed in unsteady-state period is related to settling time $t_{s}$ and duty cycle $u(t)$.

$$
\begin{aligned}
E_{u s} & =\sum_{t=1}^{t_{s}} U(t) \times I(t) \times 1 \times u(t) \\
& =\sum_{t=1}^{t_{s}} P(t) \times u(t) \approx \sum_{t=1}^{t_{s}} 450 \times u(t)
\end{aligned}
$$

Another energy consumption indicator used in this paper is steady-state energy intensity $E I_{s s}$, which is defined and calculated by using Equation (19). In the steady-state, duty cycle maintains in a small range. Energy consumption in steady-state is expected to be proportional to the length of time. It is therefore 
worth to investigate the energy consumption per unit time in steady-state. As shown in Equation (19), the steady-state energy intensity $E I_{s s}$ is a ratio of energy consumption $E_{s s}$ to the length of time $t_{s s}$, in steady-state.

$$
E I_{s s}=\frac{E_{s s}}{t_{s s}}=\frac{\sum_{t_{s}}^{t_{\text {end }}} 450 \times u(t)}{t_{\text {end }}-t_{s}}
$$

\section{Experimental Water Heating System}

To verify the energy efficiency of the proposed e-RBF-PID controller, experiments have been conducted on a water heating system. The experimental system set up is shown in Figure 3 and the schematic diagram of the experimental system is illustrated in Figure 4.

The specifications of devices used in the experiment are presented in Table 1. Four controllers (on-off, PID, RBF-PID and e-RBF-PID) are developed on the platform of Python on the PC host. Water temperature is measured by using DS18B20 sensor per second during the control and transmitted to PC host via a temperature measurement chip. Duty-cycle, which is defined as a percentage of

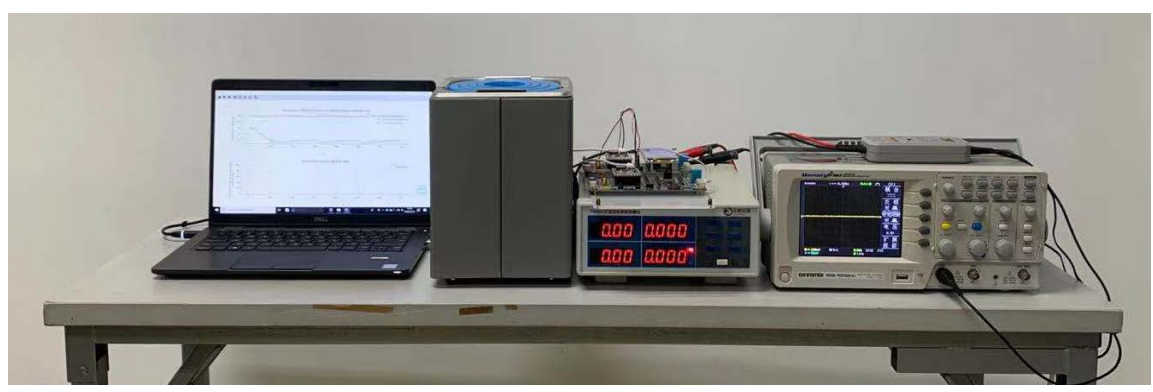

Figure 3. Configuration of experimental heating system.

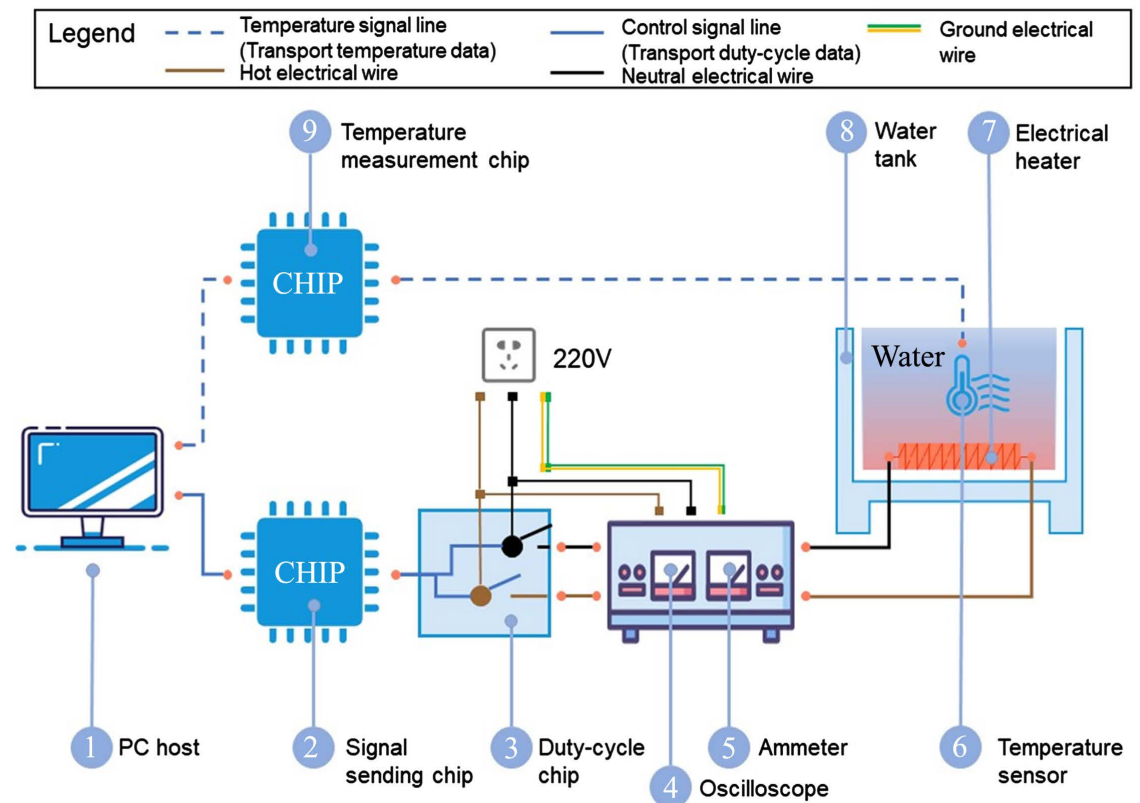

Figure 4. Schematic diagram of the experimental system. 
Table 1. Specifications of the experimental heating system.

\begin{tabular}{|c|c|c|c|}
\hline Device & Brand & Model & Specifications \\
\hline \multirow[t]{2}{*}{ PC host } & DELL & Latitude 5300 & CPU: Intel i5-8265U \\
\hline & & & RAM: 8 GB \\
\hline Signal sending chip & 01Studio & PYBv1.1-CN & Base: STM32F405RGT6 \\
\hline \multirow{2}{*}{ PWM chip } & \multirow{2}{*}{ Yueyu } & \multirow{2}{*}{ YYAC-3S } & Input voltage: $3.3-5 \mathrm{~V}$ \\
\hline & & & Duty-cycle: $0 \%-100 \%$ \\
\hline $\begin{array}{c}\text { Temperature } \\
\text { measurement chip }\end{array}$ & 01Studio & PYBv1.1-CN & Base: STM32F405RGT6 \\
\hline \multirow[t]{2}{*}{ Oscilloscope } & GW-INSTEK & GDS-1072A-U & Bandwidths: $70 \mathrm{MHz}$ \\
\hline & & & Sampling rate: $1 \mathrm{GSa} / \mathrm{s}$ \\
\hline \multirow{3}{*}{ Ammeter } & \multirow{3}{*}{$\begin{array}{l}\text { Yongpeng } \\
\text { Instrument }\end{array}$} & & Voltage range: 5 - $400 \mathrm{~V}$ \\
\hline & & PW9901 & Current range: $0.005-20 \mathrm{~A}$ \\
\hline & & & Power range: $0.1 \mathrm{~W}-16.5 \mathrm{KW}$ \\
\hline \multirow[t]{2}{*}{ Differential probe } & \multirow[t]{2}{*}{ ETA } & \multirow[t]{2}{*}{ ETA-5002 } & Bandwidths: $25 \mathrm{MHz}$ \\
\hline & & & Maximum voltage: $1300 \mathrm{~V}$ \\
\hline \multirow[t]{2}{*}{ Water tank } & \multirow[t]{2}{*}{ Tanghe } & \multirow[t]{2}{*}{$\mathrm{HH}-1$} & Size: $150 \times 150 \times 150 \mathrm{~mm}$ \\
\hline & & & Materia: 304 stainless steel \\
\hline \multirow[t]{2}{*}{ Temperature sensor } & \multirow[t]{2}{*}{ 01Studio } & \multirow[t]{2}{*}{ DS18B20 } & Range: $-55^{\circ} \mathrm{C}-125^{\circ} \mathrm{C}$ \\
\hline & & & Precision: $0.5^{\circ} \mathrm{C}$ \\
\hline
\end{tabular}

time span that electrical heater is on in one second over the one second, is computed in control process. Based on its definition, duty-cycle is proportional to the energy consumption for the controller. The calculated duty-cycle signal is sent to a PWM chip via a signal sending chip. The PWM chip accordingly modifies the power input to the electrical heater in the water tank. Table 2 shows the scenarios for the experiments. The energy consumption for the four controllers under the three scenarios are investigated through experiments. Apart from reference water temperature, acceptable error bands are also set. The values of acceptable error bands are defined as the value of reference temperature $\pm 0.5^{\circ} \mathrm{C}$.

Before carrying out experiments, the temperature sensor was calibrated. The uncertainty of measured water temperature was evaluated by adopting statistical analysis of 20 observations at room temperature. The calculated uncertainty of measured water temperature is $29^{\circ} \mathrm{C} \pm 0.015^{\circ} \mathrm{C}$.

\section{Results and Discussion}

In this section, the results identifying the performance of the four controllers under three scenarios are shown. The performances of the four controllers are discussed and compared.

\subsection{Experimental Results: Temperature Tracking Performance}

Figure 5 shows the performance of four controllers under the Scenario 1. The 


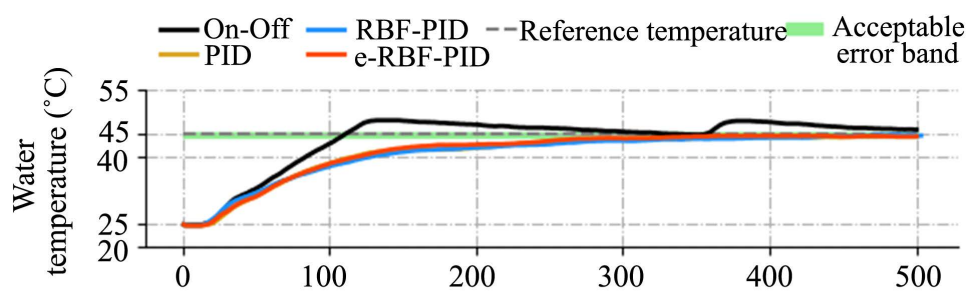

(a)

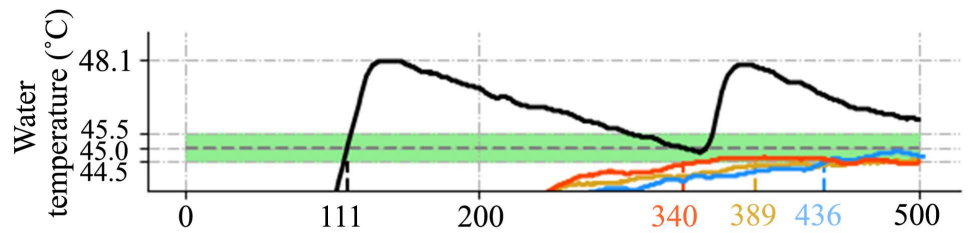

(b)

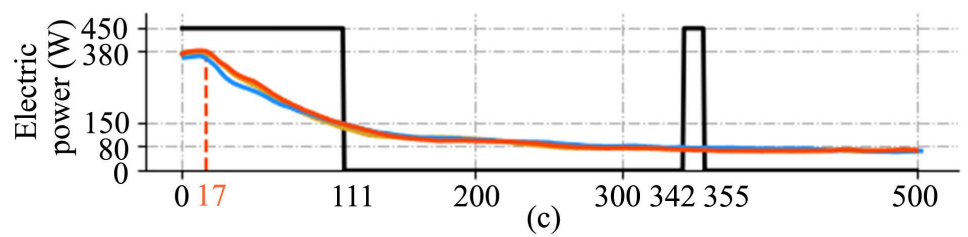

Time (s)

Figure 5. Comparison between the four controllers, $T_{R}=45^{\circ} \mathrm{C}$; (a) global tracking performance; (b) narrow-down; (c) energy consumption variation.

Table 2. Scenarios for the experiments.

\begin{tabular}{|c|c|c|c|c|c|c|}
\hline Scenario & Number & $\begin{array}{c}\text { Initial water } \\
\text { temperature } \\
T_{(0)}\left({ }^{\circ} \mathrm{C}\right)\end{array}$ & $\begin{array}{c}\text { Reference water } \\
\text { temperature } \\
T_{r}\left({ }^{\circ} \mathrm{C}\right)\end{array}$ & Controller & $\begin{array}{c}\text { Water } \\
\text { volume } \\
(\mathrm{mL})\end{array}$ & $\begin{array}{c}\text { Experiment } \\
\text { end time } \\
t_{\text {end }}(\mathrm{s})\end{array}$ \\
\hline \multirow{4}{*}{1} & 1 & 25 & 45 & On-off & 500 & 500 \\
\hline & 2 & 25 & 45 & PID & 500 & 500 \\
\hline & 3 & 25 & 45 & RBF-PID & 500 & 500 \\
\hline & 4 & 25 & 45 & e-RBF-PID & 500 & 500 \\
\hline \multirow{4}{*}{2} & 5 & 25 & 55 & On-off & 500 & 500 \\
\hline & 6 & 25 & 55 & PID & 500 & 500 \\
\hline & 7 & 25 & 55 & RBF-PID & 500 & 500 \\
\hline & 8 & 25 & 55 & e-RBF-PID & 500 & 500 \\
\hline \multirow{4}{*}{3} & 9 & 25 & 65 & On-off & 500 & 800 \\
\hline & 10 & 25 & 65 & PID & 500 & 800 \\
\hline & 11 & 25 & 65 & RBF-PID & 500 & 800 \\
\hline & 12 & 25 & 65 & e-RBF-PID & 500 & 800 \\
\hline
\end{tabular}

tracking performance of the four controllers is presented in Figure 5(a) and Figure 5(b). Figure 5(a) shows it takes the shortest time, $111 \mathrm{~s}$, for on-off controller to heat water approaching up to the reference temperature. In the heating process, a noticeable overshoot of water temperature, $3.1^{\circ} \mathrm{C}$, is found. Compared with the on-off controller, the trajectories of water temperature controlled by the 
other three controllers are much smoother and there are no overshoots observed. It is worth to note that the developed e-RBF-PID outperforms on-off, PID and RBF-PID controller because it has the lowest settling time. As shown in Figure 5(b), the settling time of e-RBF-PID is $340 \mathrm{~s}$. After $340 \mathrm{~s}$, the water temperature is within the acceptable error bands. For PID and RBF-PID controllers, their settling time is $389 \mathrm{~s}$ and $436 \mathrm{~s}$, respectively.

The energy consumption for the four controllers is demonstrated in Figure 5 (c). The energy consumption for on-off controller is 450 watts from $0 \mathrm{~s}$ to $111 \mathrm{~s}$ and $342 \mathrm{~s}$ to $355 \mathrm{~s}$. The profiles of energy consumption for the other three controllers share very similar trajectories. The energy consumption for the three controllers is close to 380 watts from $0 \mathrm{~s}$ to $17 \mathrm{~s}$ and afterwards, it gradually declines to 80 watts.

The experimental results of Scenario 2 (reference temperature $55^{\circ} \mathrm{C}$ ) are shown in Figure 6. In this scenario, on-off controller spends the shortest time, $158 \mathrm{~s}$, in heating water to up to the reference temperature with large overshoots, $3.1^{\circ} \mathrm{C}$. As shown in Figure 6(b), the settling time of PID and e-RBF-PID controller is $435 \mathrm{~s}$ and $272 \mathrm{~s}$, respectively. Nevertheless, RBF-PID controller in this scenario is not able to heat water up to the reference temperature before $500 \mathrm{~s}$.

In this scenario, on-off controller stops heating at $158 \mathrm{~s}$ for the first time. During the rest of time, the controller reheats water in the period from $232 \mathrm{~s}$ to $252 \mathrm{~s}, 326 \mathrm{~s}$ to $341 \mathrm{~s}$, and $422 \mathrm{~s}$ to $435 \mathrm{~s}$. For the other three controllers, the energy consumption begins to decrease starting from $33 \mathrm{~s}$ for RBF-PID controller, $44 \mathrm{~s}$ for e-RBF-PID controller and $53 \mathrm{~s}$ for PID controller, respectively.

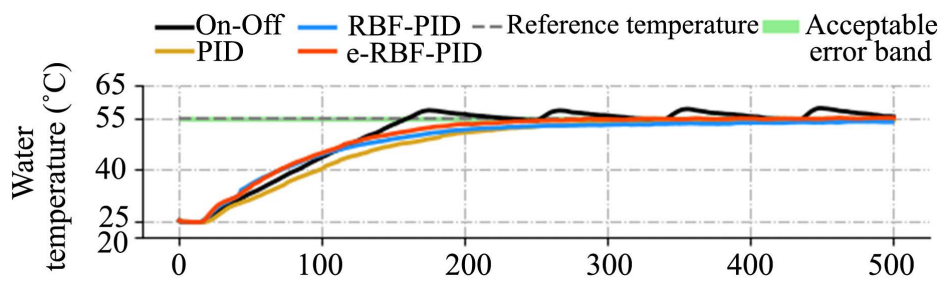

(a)

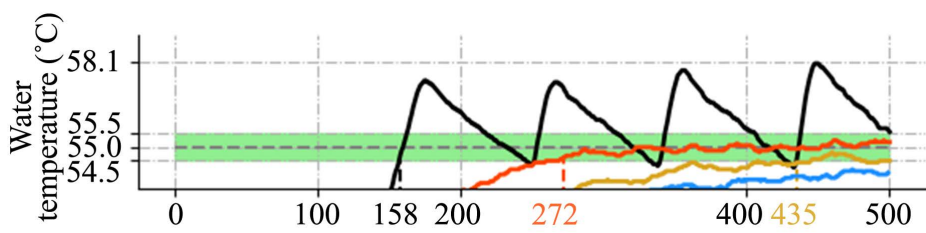

(b)

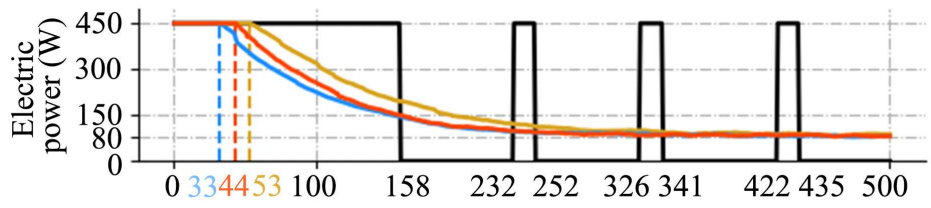

(c)

Time (s)

Figure 6. Comparison between the four controllers, $T_{R}=55^{\circ} \mathrm{C}$; (a) global tracking performance; (b) narrow-down; (c) energy consumption variation. 
Figure 7 shows the experimental results of the third scenarios (reference temperature $65^{\circ} \mathrm{C}$ ). The settling time of on-off controller is only $198 \mathrm{~s}$, much shorter than the RBF-PID controller, $334 \mathrm{~s}$, followed by e-RBF-PID controller, $365 \mathrm{~s}$. Noticeably, the settling time of PID controller in this scenario is $716 \mathrm{~s}$. The energy consumption for on-off controller is demonstrated in Figure 7 (c). The on-off controller stops heating at $198 \mathrm{~s}$. The controller starts to reheat water when the water temperature is lower than the reference level and there are seven times that the controller switches from off-state to on-state. The energy consumption for other three controllers is 450 watts from $0 \mathrm{~s}$ to $126 \mathrm{~s}$ and afterwards, it gradually approaches to 100 watts.

The settling time of the four controllers are presented in Table 3. The settling time of on-off controller is N/A because it failed to maintain water temperature at the desired levels. The settling time of RBF-PID controller is longer than that

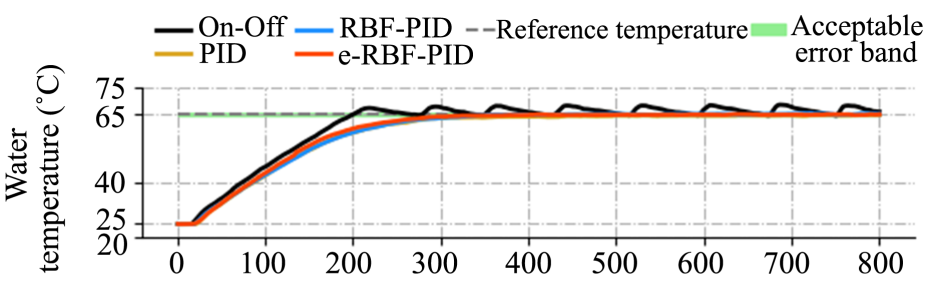

(a)

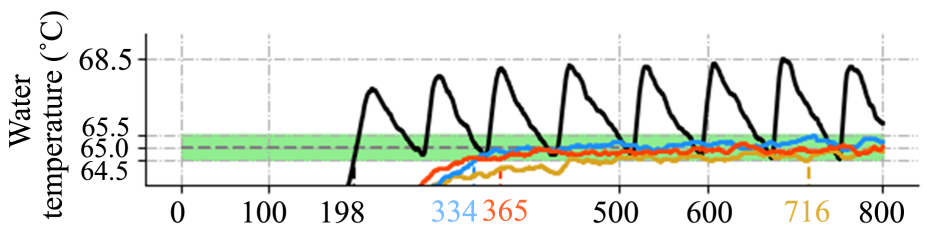

(b)

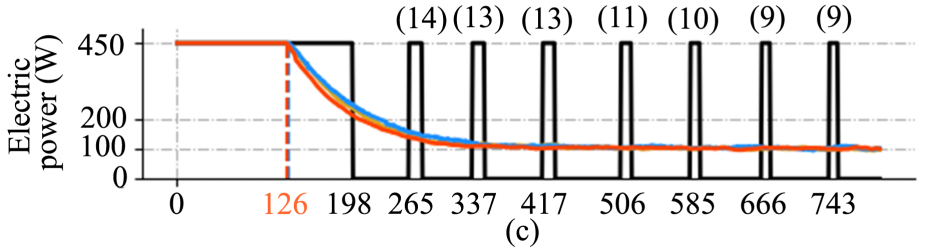

Time (s)

Figure 7. Comparison between the four controllers, $T_{R}=65^{\circ} \mathrm{C}$; (a) global tracking performance; (b) narrow-down; (c) energy consumption variation.

Table 3. Comparison of settling time of the four controllers.

\begin{tabular}{cccccc}
\hline & On-off & PID & RBF-PID & e-RBF-PID & $\begin{array}{c}\text { Savings } \\
\text { (e-RBF-PID to PID) [\%] }\end{array}$ \\
\hline $\begin{array}{c}\text { Settling time } \\
(\text { Scenario } 1)[\mathrm{s}]\end{array}$ & N/A & 389 & 436 & 340 & 12.6 \\
$\begin{array}{c}\text { Settling time } \\
(\text { Scenario 2) }[\mathrm{s}]\end{array}$ & N/A & 435 & N/A & 272 & 37.5 \\
$\begin{array}{c}\text { Settling time } \\
\text { (Scenario 3) }[\mathrm{s}]\end{array}$ & N/A & 716 & 334 & 365 & 49.0 \\
\hline
\end{tabular}


of PID controller in the Scenario 1 but shorter in the Scenario 3. In all the scenarios, the e-RBF-PID controller has the shortest settling time, achieving $12.6 \%$ (Scenario 1), 37.5\% (Scenario 2) and 49\% (Scenario 3) of time savings compared to PID controller.

\subsection{The Variation of Gain Coefficients in RBF and e-RBF-PID Controllers}

The gain coefficients of PID controllers in all the scenarios are fixed. In RBF-PID and e-RBF-PID controllers, they are varied with time. The variation of PID gain coefficients are demonstrated in Figures 8-10. It is noticed that in all the three scenarios, the value of proportional gain coefficient $K_{p}(t)$ in both RBF-PID and e-RBF-PID controllers undergoes a very slight change. In contrast, the value of integral gain coefficient $K_{i}(t)$ in RBF-PID and e-RBF-PID controllers changes significantly. Moreover, in all the three scenarios, the value of derivative gain coefficient $K_{d}(t)$ in RBF-PID and e-RBF-PID controllers rapidly changes in the very beginning.

\subsection{Experimental Results: Energy Consumption for Controllers}

As shown in Tables 4-6, the energy consumption performances are analysed by using the two energy performance indicators: unsteady-state energy $E_{u s}$ and steady-state energy intensity $E I_{S S}$. It is noticed that in each scenario, the steady-state energy intensity $E I_{s s}$ of PID, RBF-PID and e-RBF-PID controllers are very similar. However, the unsteady-state energy $E_{u s}$ of controllers has a large difference. Figure 11 shows the comparison of unsteady-state energy $E_{u s}$

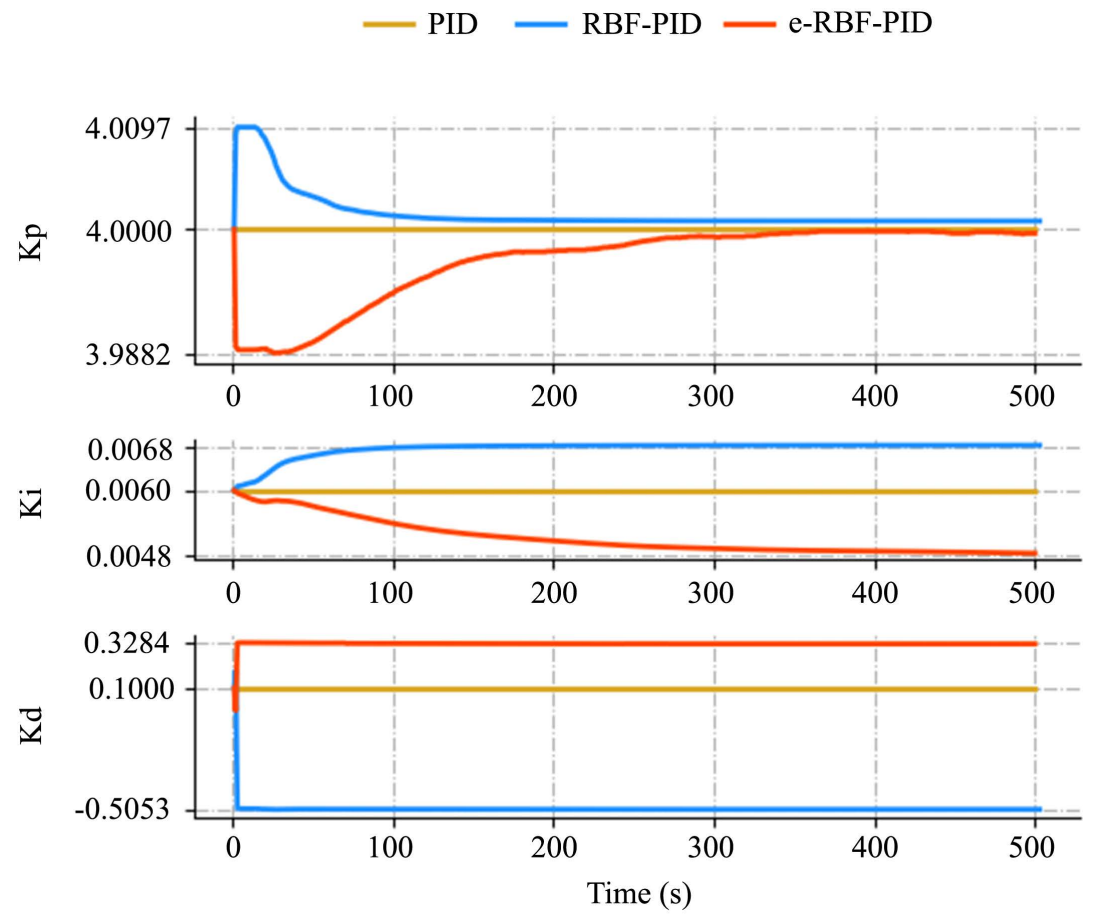

Figure 8. Tuning PID gain coefficients by PID, RBF-PID, e-RBF-PID $\left(T_{R}=45^{\circ} \mathrm{C}\right)$. 
Table 4. Assessment of experiments under the Scenario 1.

\begin{tabular}{|c|c|c|c|c|c|}
\hline \multicolumn{2}{|c|}{ Number of experiments } & 1 & 2 & 3 & 4 \\
\hline \multicolumn{2}{|c|}{ Controller } & On-off & PID & RBF-PID & e-RBF-PID \\
\hline \multirow{2}{*}{$\begin{array}{l}\text { Heating } \\
\text { process }\end{array}$} & Settling time $[\mathrm{s}]$ & $\mathrm{N} / \mathrm{A}$ & 389 & 436 & 340 \\
\hline & $\begin{array}{l}\text { Unsteady-state energy } \\
\qquad E_{u s}[\mathrm{kWh}]\end{array}$ & $3.42 \times 10^{-3}$ & $3.19 \times 10^{-3}$ & $3.42 \times 10^{-3}$ & $3.06 \times 10^{-3}$ \\
\hline \multirow{4}{*}{$\begin{array}{c}\text { Maintenance } \\
\text { process }\end{array}$} & $\begin{array}{l}\text { Length of steady-state } \\
\text { period } t_{s s}[\mathrm{~s}]\end{array}$ & N/A & 111 & 64 & 160 \\
\hline & $\begin{array}{l}\text { Steady-state energy } \\
\qquad E_{s s}[\mathrm{kWh}]\end{array}$ & N/A & $4.25 \times 10^{-4}$ & $2.43 \times 10^{-4}$ & $6.23 \times 10^{-4}$ \\
\hline & $\begin{array}{l}\text { Steady-state energy } \\
\text { intensity } E I_{s s}[\mathrm{~kW}]\end{array}$ & N/A & $3.83 \times 10^{-6}$ & $3.80 \times 10^{-6}$ & $3.89 \times 10^{-6}$ \\
\hline & $\begin{array}{l}\text { Absolute mean } \\
\text { static error }\left[{ }^{\circ} \mathrm{C}\right]\end{array}$ & N/A & 0.44 & 0.30 & 0.38 \\
\hline
\end{tabular}

Table 5. Assessment of experiments under the Scenario 2.

\begin{tabular}{|c|c|c|c|c|c|}
\hline \multicolumn{2}{|c|}{ Number of experiments } & 5 & 6 & 7 & 8 \\
\hline \multicolumn{2}{|c|}{ Controller } & On-off & PID & RBF-PID & e-RBF-PID \\
\hline \multirow{2}{*}{$\begin{array}{l}\text { Heating } \\
\text { process }\end{array}$} & Settling time [s] & N/A & 435 & N/A & 272 \\
\hline & $\begin{array}{c}\text { Unsteady-state energy } \\
\qquad E_{u s}[\mathrm{kWh}]\end{array}$ & $5.63 \times 10^{-3}$ & $5.37 \times 10^{-3}$ & $4.80 \times 10^{-3}$ & $3.84 \times 10^{-3}$ \\
\hline \multirow{4}{*}{$\begin{array}{l}\text { Maintenance } \\
\text { process }\end{array}$} & $\begin{array}{l}\text { Length of steady-state } \\
\text { period } t_{s s}[\mathrm{~s}]\end{array}$ & $\mathrm{N} / \mathrm{A}$ & 65 & $\mathrm{~N} / \mathrm{A}$ & 228 \\
\hline & $\begin{array}{c}\text { Steady-state energy } \\
\qquad E_{s s}[\mathrm{kWh}]\end{array}$ & $\mathrm{N} / \mathrm{A}$ & $3.45 \times 10^{-4}$ & N/A & $1.19 \times 10^{-3}$ \\
\hline & $\begin{array}{l}\text { Steady-state energy } \\
\text { intensity } E I_{s s}[\mathrm{~kW}]\end{array}$ & $\mathrm{N} / \mathrm{A}$ & $5.31 \times 10^{-6}$ & $\mathrm{~N} / \mathrm{A}$ & $5.22 \times 10^{-6}$ \\
\hline & $\begin{array}{l}\text { Absolute mean } \\
\text { static error }\left[{ }^{\circ} \mathrm{C}\right]\end{array}$ & $\mathrm{N} / \mathrm{A}$ & 0.37 & $\mathrm{~N} / \mathrm{A}$ & 0.19 \\
\hline
\end{tabular}

Table 6. Assessment of experiments under the Scenario 3.

\begin{tabular}{|c|c|c|c|c|c|}
\hline \multicolumn{2}{|c|}{ Number of experiments } & 9 & 10 & 11 & 12 \\
\hline \multicolumn{2}{|c|}{ Controller } & On-off & PID & RBF-PID & e-RBF-PID \\
\hline \multirow[b]{2}{*}{$\begin{array}{l}\text { Heating } \\
\text { process }\end{array}$} & Settling time $[\mathrm{s}]$ & N/A & 716 & 334 & 365 \\
\hline & $\begin{array}{c}\text { Unsteady-state energy } \\
\qquad E_{u s}[\mathrm{kWh}]\end{array}$ & $7.89 \times 10^{-3}$ & $8.67 \times 10^{-3}$ & $6.37 \times 10^{-3}$ & $6.26 \times 10^{-3}$ \\
\hline \multirow{4}{*}{$\begin{array}{l}\text { Maintenance } \\
\text { process }\end{array}$} & $\begin{array}{l}\text { Length of steady-state } \\
\text { period } t_{s s}[\mathrm{~s}]\end{array}$ & $\mathrm{N} / \mathrm{A}$ & 716 & 334 & 365 \\
\hline & $\begin{array}{l}\text { Steady-state energy } \\
E_{S S}[\mathrm{kWh}]\end{array}$ & $\mathrm{N} / \mathrm{A}$ & $5.06 \times 10^{-4}$ & $3.00 \times 10^{-3}$ & $2.72 \times 10^{-3}$ \\
\hline & $\begin{array}{l}\text { Steady-state energy } \\
\text { intensity } E I_{s s}[\mathrm{~kW}]\end{array}$ & $\mathrm{N} / \mathrm{A}$ & $6.02 \times 10^{-6}$ & $6.44 \times 10^{-6}$ & $6.26 \times 10^{-6}$ \\
\hline & $\begin{array}{l}\text { Absolute mean } \\
\text { static error }\left[{ }^{\circ} \mathrm{C}\right]\end{array}$ & N/A & 0.26 & 0.15 & 0.24 \\
\hline
\end{tabular}



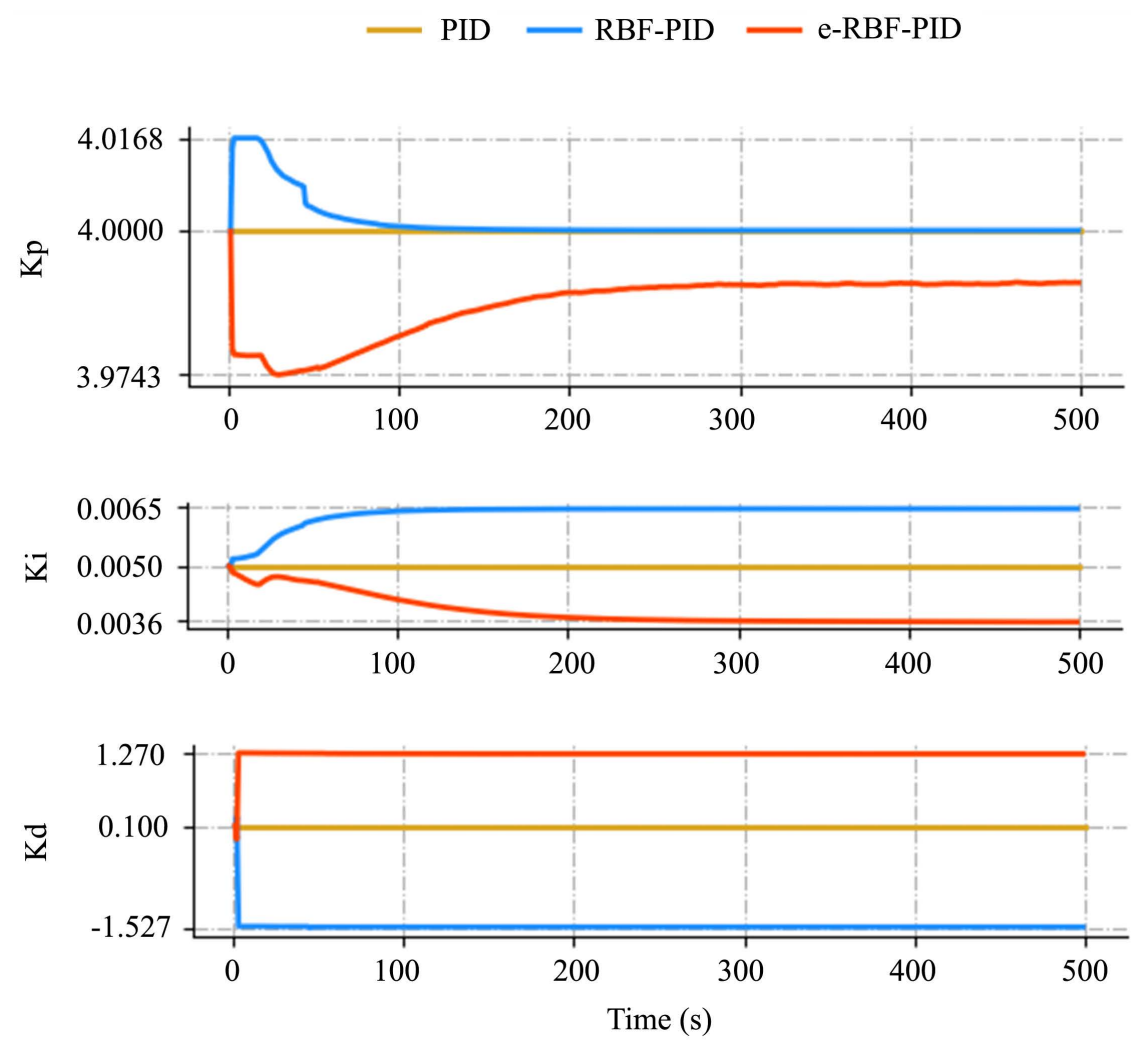

Figure 9. Tuning PID gain coefficients by PID, RBF-PID, e-RBF-PID $\left(T_{R}=55^{\circ} \mathrm{C}\right)$.
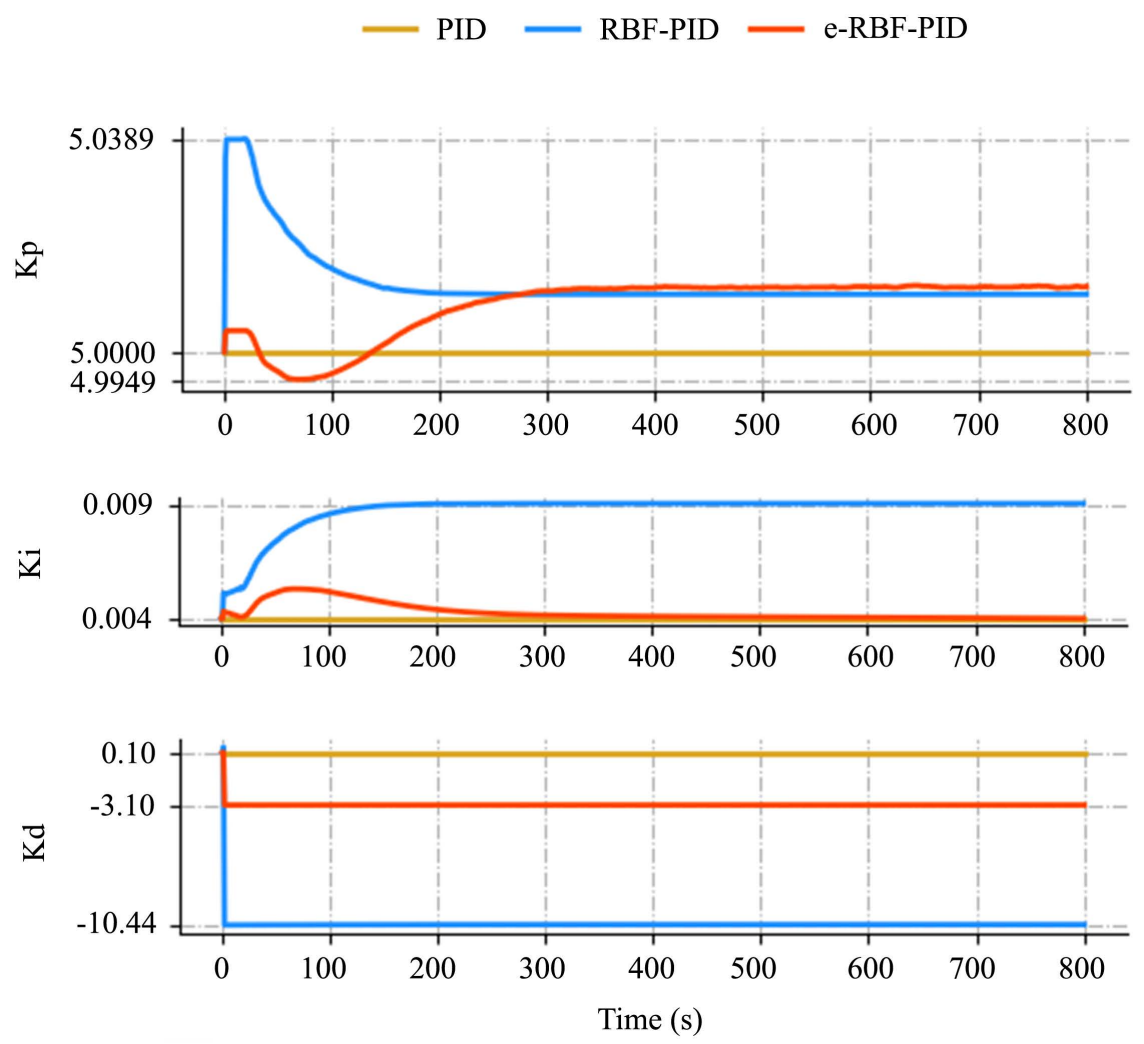

Figure 10. Tuning PID gain coefficients by PID, RBF-PID, e-RBF-PID $\left(T_{R}=65^{\circ} \mathrm{C}\right)$. 


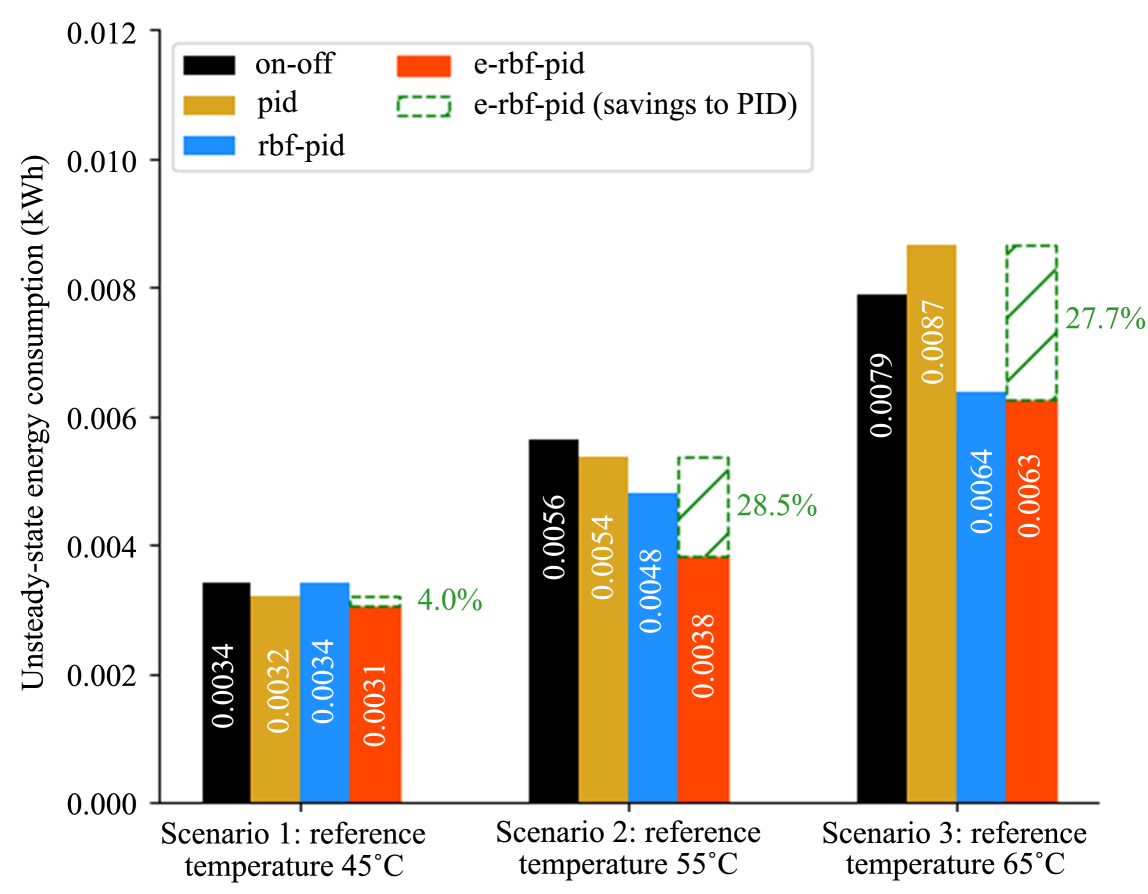

Figure 11. Comparison of unsteady-state energy between controllers.

of each controller. It can be seen that compared to PID controller, the e-RBF-PID consumes less unsteady-state energy and the relative energy savings are respectively $4.0 \%$ in the Scenario 1, 28.5\% in the Scenario 2 and 27.7\% in the Scenario 3. In all the scenarios, the e-RBF-PID controller consumed also less energy consumption than the RBF-PID controller, which did not heat water up to the reference temperature in the scenario. Therefore the e-RBF-PID controller has high energy efficiency in unsteady-state period and good control accuracy in steady-state period.

\section{Conclusions}

In this paper, an enhanced self-tuning RBF-PID (e-RBF-PID) controller is developed for enhancing the control efficiency during control process. The advantage of using this controller is verified through conducting experiments on a water heating system. The performance of e-RBF-PID controller is further analysed and compared to other three controllers: on-off, PID and RBF-PID controller.

The experimental results show that the developed e-RBF-PID controller had short settling time, low energy consumption and high control accuracy. Compared to PID controller, the developed e-RBF-PID controller is capable of offering time-savings up to $49.0 \%$ and energy-savings up to $28.5 \%$, illustrating the advantage of e-RBF-PID controller in energy efficiency.

\section{Acknowledgements}

This research was financially supported by Ningbo Natural Science Foundation 
Project (2019A610094) and Hebei province international science and technology cooperation fundamental project in North China Institute of Science and Technology (20594501D).

\section{Credit Author Statement}

Zu Wang: Conceptualization, Methodology, Software, Formal analysis, Investigation, Data Curation, Writing Original Draft. Liang Xia: Conceptualization, Methodology, Formal analysis, Investigation, Writing Review \& Editing, Supervision, Project administration, Funding acquisition. John Kaiser Calautit: Writing, Review \& Editing, supervision. Xinru Wang: Funding acquisition, validation. Danwei Jiang: Funding acquisition, validation. Song Pan: Resources, Editing. Jinshun Wu: Resources, Editing.

\section{Conflicts of Interest}

The authors declare no conflicts of interest regarding the publication of this paper.

\section{References}

[1] Diaz-Mendez, S.E., Patiño-Carachure, C. and Herrera-Castillo, J.A. (2014) Reducing the Energy Consumption of an Earth-Air Heat Exchanger with a PID Control System. Energy Conversion and Management, 77, 1-6.

https://doi.org/10.1016/j.enconman.2013.09.033

[2] Lei, Z. and Zhou, Y. (2018) A Kind of Nonlinear PID Controller for Refrigeration Systems Based on Vapour Compression. IFAC-PapersOnLine, 51, 716-721. https://doi.org/10.1016/j.ifacol.2018.06.188

[3] Carreño-Zagarra, J.J., Villamizar, R., Moreno, J.C. and Guzmán, J.L. (2018) Active Disturbance Rejection and PID Control of a One-Stage Refrigeration Cycle. IFAC-PapersOnLine, 51, 444-449. https://doi.org/10.1016/j.ifacol.2018.06.135

[4] Moradi, H. (2016) PID-Fuzzy Control of Air Handling Units in the Presence of Uncertainty. International Journal of Thermal Sciences, 109, 123-135. https://doi.org/10.1016/j.ijthermalsci.2016.05.024

[5] Wang, J., Zhang, C., Jing, Y. and An, D. (2007) Study of Neural Network PID Control in Variable-Frequency Air-Conditioning System. IEEE International Conference on Control and Automation, Guangzhou, 30 May-1 June 2007, 317-322.

[6] Ardehali, M.M., Smith, T.F., et al. (1996) Development of Proportional-Sum-Derivative Control Methodology. Solar Energy, 57, 251-260. https://doi.org/10.1016/S0038-092X(96)00058-8

[7] Ardehali, M.M., Saboori, M. and Teshnelab, M. (2004) Numerical Simulation and Analysis of Fuzzy PID and PSD Control Methodologies as Dynamic Energy Efficiency Measures. Energy Conversion and Management, 45, 1981-1992. https://doi.org/10.1016/j.enconman.2003.11.003

[8] Jahedi, G. and Ardehali, M.M. (2011) Genetic Algorithm-Based Fuzzy-PID Control Methodologies for Enhancement of Energy Efficiency of a Dynamic Energy System. Energy Conversion and Management, 52, 725-732. https://doi.org/10.1016/j.enconman.2010.07.051

[9] Soyguder, S., Karakose, M. and Alli, H. (2009) Design and Simulation of 
Self-Tuning PID-Type Fuzzy Adaptive Control for an Expert HVAC System. Expert Systems with Applications, 36, 4566-4573.

https://doi.org/10.1016/j.eswa.2008.05.031

[10] Attaran, S.M., Yusof, R. and Selamat, H. (2016) A Novel Optimization Algorithm Based on Epsilon Constraint-RBF Neural Network for Tuning PID Controller in Decoupled HVAC System. Applied Thermal Engineering, 99, 613-624.

https://doi.org/10.1016/j.applthermaleng.2016.01.025

[11] Pinnella, M.J., Wechselberger, E., Hittle, D.C. and Pedersen, C.O. (1986) Self-Tuning Digital Integral Control. ASHRAE Trans United States. 92.

[12] Krakow, K.I. and Lin, S. (1995) PI Control of Fan Speed to Maintain Constant Discharge Pressure. American Society of Heating, Refrigerating and Air-Conditioning Engineers.

[13] Nesler, C.G. and Stoecker, W.F. (1984) Selecting the Proportional and Integral Constants in the Direct Digital Control of Discharge Air Temperature. ASHRAE Transactions, 90, 834-845.

[14] Shavit, G. and Brandt, S.G. (1982) Dynamic Performance of a Discharge Air Temperature System with a p-1 Controller. AIChE Journal, 24, 9.

[15] Wu, W., Zhong, S. and Zhou, G. (2013) A Study on PID Intelligent Optimization Based on Radial Basis Function Neural Networks. 2013 3rd International Conference on Consumer Electronics, Communications and Networks, Xianning, 20-22 November 2013, 57-60. https://doi.org/10.1109/CECNet.2013.6703271

[16] Beyhan, S. and Alc1, M. (2010) Stable Modeling Based Control Methods Using a New RBF Network. ISA Transactions, 49, 510-518. https://doi.org/10.1016/j.isatra.2010.04.005

[17] Zhang, M., Wang, X. and Liu, M. (2005) Adaptive PID Control Based on RBF Neural Network Identification. 17 th IEEE International Conference on Tools with Artificial Intelligence (ICTAP05), Hong Kong, 14-16 November 2005, 683.

[18] Powell, M.J.D. (1987) Radial Basis Functions Approximations to Polynomials. Proceedings 12 th Biennial Numerical Analysis Conference.

[19] Ulpiani, G., Borgognoni, M., Romagnoli, A. and Di Perna, C. (2016) Comparing the Performance of on/off, PID and Fuzzy Controllers Applied to the Heating System of an Energy-Efficient Building. Energy and Buildings, 116, 1-17.

https://doi.org/10.1016/j.enbuild.2015.12.027

[20] Yabanova, İ. and Keçebaş, A. (2013) Development of ANN Model for Geothermal District Heating System and a Novel PID-Based Control Strategy. Applied Thermal Engineering, 51, 908-916. https://doi.org/10.1016/j.applthermaleng.2012.10.044

[21] Yue, W.Q., Feng, S.X. and Zhang, Q. (2010) An Auto-Adaptive PID Control Method Based on RBF Neural Network. 2010 3rd International Conference on Advanced Computer Theory and Engineering (ICACTE), Chengdu, 20-22 August 2010, V3-503-V3-505. https://doi.org/10.1109/ICACTE.2010.5579863

[22] Chen, Y.F., Xu, S., Cao, R. and Zhou, T. (2011) The Study and Simulation of PID Control Based on RBF Neural Network. Proceedings of 2011 International Conference on Electronic \& Mechanical Engineering and Information Technology, Harbin, 12-14 August 2011, 3453-3456.

https://doi.org/10.1109/EMEIT.2011.6023826

[23] Zhang, Y., Zhao, D. and Zhang, J. (2011) Research on PID Controller Based on RBF Neural Network. Proceedings of 2011 International Conference on Electronics and Optoelectronics, Dalian, 29-31 July 2011, V1-443-V1-445. 
[24] Li, Z., Hu, J. and Huo, X. (2012) PID Control Based on RBF Neural Network for Ship Steering. 2012 World Congress on Information and Communication Technologies, Trivandrum, 30 October-2 November 2012, 1076-1080.

https://doi.org/10.1109/WICT.2012.6409235 


\section{Nomenclature}

Variable Description

$X \quad$ Input vector to the RBF neural network

$C_{j} \quad$ Center vector of the $j$ th node in the hidden layer

$b_{j} \quad$ Band width of the $j$ th node in the hidden layer

$h_{j} \quad$ Output of the th node in the hidden layer

$w_{j} \quad$ Weight of $j$ th node in the hidden layer

$T_{m}(t) \quad$ Modelled water temperature at the time $t$

$J(t) \quad$ Jacobian information at the time $t$

$T_{\text {ref }} \quad$ Desired water temperature

$T(t) \quad$ Measured water temperature at the time $t$

$e(t) \quad$ Error temperature at the time $t$

$u(t) \quad$ Duty cycle at the time $t$ (min: 0 , max: 100)

$u(t-1) \quad$ Duty cycle at the time $t-1$ (min: 0 , max: 100)

$e(t-1) \quad$ Error temperature at the time $t-1$

$e(t-2) \quad$ Error temperature at the time $t-2$

$K_{p}(t) \quad$ Proportional gain coefficient at the time $t$

$K_{i}(t) \quad$ Integral gain coefficient at the time $t$

$K_{d}(t) \quad$ Derivative gain coefficient at the time $t$

$K_{p}(t-1)$ Proportional gain coefficient at the time $t-1$

$K_{i}(t-1) \quad$ Integral gain coefficient at the time $t-1$

$K_{d}(t-1)$ Derivative gain coefficient at the time $t-1$

$\Delta K_{p}(t) \quad$ The change of proportional gain coefficient at the time $t$ -

$\Delta K_{i}(t) \quad$ The change of integral gain coefficient at the time $t$

$\Delta K_{d}(t) \quad$ The change of derivative gain coefficient at the time $t$

$E(t) \quad$ Error performance index at the time $t$

$\eta_{1} \quad$ Learning rate of proportional gain coefficient

$\eta_{2} \quad$ Learning rate of integral gain coefficient

$\eta_{3} \quad$ Learning rate of derivative gain coefficient

$U(t) \quad$ Voltage drop for the electrical heating coil

$I(t) \quad$ Current through the electrical heating coil

$P(t) \quad$ Rated power of the electrical heating coil

$E_{\text {us }} \quad$ Energy consumption for a controller in unsteady-state period

$-$

$-$

[V]

[A]

[W]

[kWh]

$E_{s s} \quad$ Energy consumption for a controller in steady-state period

[kWh]

$t_{s s} \quad$ Length of steady-state period

[s]

$E I_{\text {ss }} \quad$ Electric energy intensity for a controller in steady-state period
Unit

$\left[{ }^{\circ} \mathrm{C}\right]$

$\left[{ }^{\circ} \mathrm{C}\right]$

$\left[{ }^{\circ} \mathrm{C}\right]$ 